\title{
El dato geográfico en la gestión del patrimonio arqueológico
}

\author{
César Parcero-Oubiña, César González-Pérez, Laboratorio de Patrimonio, Consejo Superior de Investigaciones Científicas
}

El concepto de patrimonio arqueológico se refiere, por definición, a elementos materiales. Una buena parte de ellos incorpora una dimensión espacial, es decir, una localización y geometría, que no sólo son atributos adjetivos, sino que son un componente sustantivo en la propia identificación y caracterización de estos elementos. Esto es algo independiente de la escala concreta de cada elemento, desde los niveles más detallados (como simples estructuras de escaso desarrollo espacial, por ejemplo un menhir) hasta los más extensos y complejos (como por ejemplo los paisajes).

La importancia de ese componente espacial ha sido por mucho tiempo desatendida, entendiendo que la localización y la representación formal de los elementos del patrimonio era una parte subsidiaria de su caracterización descriptiva. De la misma manera que se anotaban algunos rasgos formales de los objetos (tamaño, tipo, etc.), se describía su localización de forma más o menos detallada. Además, los modelos de caracterización manejados han sido, también por mucho tiempo, modelos basados en la descripción narrativa de cada elemento singular del patrimonio como una unidad autocontenida.

El creciente desarrollo de las tecnologías digitales de representación cartográfica de la realidad (específicamente de los llamados Sistemas de Información Geográfica, SIG en adelante) ha abierto, sobre todo en las dos últimas décadas, un campo tecnológico nuevo para el manejo y análisis de la información patrimonial. Sin embargo, la incorporación de los registros patrimoniales a ese nuevo marco tecnológico apenas ha llevado aparejado el desarrollo de modelos ontológicos específicos para definir de qué manera deberian ser modelizados los elementos del patrimonio para ser tratados en forma de información y, concretamente en este caso, de "información geográfica". Una dimensión especialmente acusada de este problema es el deficiente tratamiento de la propia dimensión espacial de los elementos patrimoniales. $Y$ un ámbito en el que estas limitaciones son claramente visibles es el escaso desarrollo de modelos específicos para la representación cartográfica de los elementos patrimoniales dentro de cualquiera de las iniciativas actualmente en marcha en los ámbitos de la estandarización de la información geográfica (para el contexto europeo, el marco de referencia que ilustra este punto es la directiva INSPIRE; véase también otras contribuciones en este mismo volumen, especialmente la de Isabel del Bosque).
Que esto haya sido así tiene sin duda mucho que ver con el hecho de que, dentro de los ámbitos posibles de aplicación de ese conjunto de tecnologías geoespaciales a la Arqueología, el relacionado con la "simple" gestión de la información ha sido sin duda menos atractivo que la exploración de las diferentes posibilidades analíticas orientadas a la investigación de problemas históricos. Este texto trata de ofrecer una serie de reflexiones generales sobre las posibilidades y condiciones para la gestión digital de la dimensión geográfica de la información arqueológica y, especialmente, de reclamar la importancia de atender a este tipo de cuestiones como un ámbito relevante de trabajo y desarrollo.

La información o, mejor, el registro arqueológico, es un ámbito complejo, como cualquier otro subconjunto de la realidad que posea un fuerte componente geográfico, aunque seguramente con condiciones específicas que lo hacen todavía más especial. De partida, la propia Arqueología como disciplina es un espacio complejo, que implica a agentes diversos. Pero además la Arqueología ha sido y es, cada vez más, un ámbito relevante más allá de ella misma: el registro no sólo es relevante en tanto que documentación histórica, sino que es una parte esencial del territorio contemplado con una mirada puramente contemporánea. Los bienes patrimoniales son elementos regulados legalmente, que afectan a las condiciones de la ordenación territorial, un componente más de los procesos de planificación y construcción del territorio en la actualidad.

De todos modos, el principal factor de complejidad del registro arqueológico es más estructural y reside en su propia naturaleza. La parte más evidente del registro es su componente material: el conjunto de evidencias tangibles que son producto o efecto de la acción social pretérita. Éste es también, con todas las salvedades que se quiera, el componente más sencillo de manejar como información geográfica: estas evidencias materiales se pueden casi siempre localizar, a menudo delimitar y siempre describir. Por definición, todo lo que puede ser localizado y descrito puede ser una parte natural de un SIG.

Pero el registro no son sólo, ni siempre, elementos singulares, fácilmente delimitables y describibles, sino también (e incluso diriamos que sobre todo) contextos formados por esos elementos y sus relaciones. Un excelente ejemplo de este tipo de contextos son los paisajes, concepto cuya fuerza articuladora 
en terrenos tan concretos como el normativo está hoy bien asentada (el ejemplo evidente, entre otros, es la Convención Europea del Paisaje). Es justo reconocer que la Arqueologia ha sido una de las disciplinas que más ha contribuido a este asentamiento (seguramente porque estaba en una buena posición para ello, como argumentan, por ejemplo, Fisher y Feinman, 2005, o Redman, 2005).

Además, el registro arqueológico supone más cosas. 0 lo que es lo mismo, hay más cosas que deben ser consideradas en cualquier proceso de documentación arqueológica. Una primera, y seguramente menos problemática, son las propias representaciones del registro, los mecanismos concretos mediante los cuales convertimos (significamos) los elementos materiales en parte propia del registro. El mejor ejemplo son las representaciones gráficas: dibujos, secciones, etc., pero también descripciones textuales, imágenes, descripciones históricas, etc. Todo esto es parte también del registro, y lo es en su doble dimensión: la material (en tanto que documentos físicos) y la intangible (discursos, valoraciones, descripciones, etc.). En todo caso, este conjunto de cosas es, como apuntábamos, menos problemático porque, en definitiva, se materializa de elementos concretos, perceptibles y describibles de formas relativamente simples.

Pero hay otras tres variables que caracterizan de forma singular a los datos arqueológicos frente a otros conjuntos de información geográfica y que resultan especialmente complejos de considerar. No necesariamente porque lo sean por su naturaleza, sino sobre todo porque no han sido típicamente problematizados en otros ámbitos de conceptualización de la información geográfica. Nos referimos a la temporalidad, la incertidumbre y la subjetividad.

La temporalidad es un rasgo especialmente relevante para el registro arqueológico que las tecnologías geoespaciales, al menos en la forma en la que las conocemos ahora, manejan con dificultad (JESSOP, 2004). El registro arqueológico es histórico $y_{1}$ como tal, la temporalidad es esencial en su propia definición. De partida, la única forma accesible de incorporar esto a un SIG es considerando que la temporalidad se implementa como uno o más atributos de los elementos materiales que forman el registro, pero esto no es una forma apropiada de solucionarlo. La temporalidad deberia de poder ser tratada como una condición de la información arqueológica, del mismo modo que lo es la espacialidad. Por ejemplo, un sistema que gestione la temporalidad como una dimensión de la información utilizaría un enfoque similar a las técnicas de versionado que existen en otros campos de aplicación como, por ejemplo, en bases de datos orientadas a objetos o en sistemas de gestión de código fuente. En estos sistemas, la modificación de una entidad de información implica la creación automática de una nueva versión de la misma, incluyendo un sello temporal que especifica el intervalo de fechas de validez de dicha versión y especifica los cambios en relación con la versión anterior. De este modo, la temporalidad es gestionada mediante una infraestructura transversal a los datos propios de las entidades de interés, mientras que los datos propiamente dichos son ajenos a la implementación de la temporalidad.

Modelizaciones detalladas de la representación del tiempo como las alcanzadas por el CIDOC-CRM (DOERR, 2003) son una muestra de la complejidad del tratamiento de esta dimensión, que en todo caso va mucho más allá de la rígida y casi siempre problemática opción de considerar el tiempo como un único atributo estático, poco o nada normalizado y extraordinariamente simplificado.

La incertidumbre es también, muy a menudo, una dimensión crucial para la información arqueológica, que sin embargo es a menudo poco o nada relevante para otros ámbitos de información geográfica. Cuando hablamos de fiabilidad en cualquier conjunto de datos geográficos, nos preguntamos por lo bien o mal que reflejen la "verdad-terreno", la existencia real de las cosas que aquellos señalen (usos del suelo, cubierta vegetal, elevación del terreno, etc.). Pero, en cualquier caso, esas realidades son siempre objetivamente identificables y mensurables (a menudo en forma simplificada de presencia/ausencia). Sin embargo, la información arqueológica no es siempre directa y objetivamente mensurable. La propia naturaleza de buena parte del registro arqueológico hace que sea frecuente el uso de conceptos como los de potencialidad, predictibilidad, etc. Sobre la base de indicadores indirectos (fuentes secundarias, el conocimiento experto de los arqueólogos, etc.) a menudo es posible "mapear" elementos cuya existencia real no es verdadera o falsa, sino simplemente probable o posible. Pero además, incluso en el caso de elementos concretos conocidos, puede también ocurrir que su componente espacial sea desconocida, incierta o cambiante en el tiempo. Las tecnologias geoespaciales, y los modelos de información geográfica de ellas derivados, son por naturaleza estáticos y deterministas. Representar en ellos información espacial difusa o variable en el tiempo no es algo natural, sino que requiere un desarrollo especifico. Burrough y Frank (1996) han compilado algunos trabajos interesantes que tratan la incertidumbre en cuanto a la delimitación espacial de entidades geográficas, pero todavía queda mucho por hacer en otros dominios de la incertidumbre.

Finalmente, la relevancia de la subjetividad en la documentación de la información arqueológica puede parecer menos evidente de entrada, aunque desde nuestro punto de vista es tal vez el factor más importante en este contexto. Y lo es en múltiples sentidos, pues hay diferentes formas de subjetividad involucradas en la creación de información arqueológica.

En primer lugar, hay un nivel de subjetividad que forma parte de la propia construcción del registro arqueológico. Este nivel, bien conocido, es el que se relaciona con las diferentes formas posibles de documentar las propias entidades básicas que forman el registro: asignarles una tipología, una adscripción, una función, una cronología... son procesos en los que, en mayor o menor medida 
y como sabemos desde hace tiempo, se involucran componentes interpretativos. Por más que éstos estén basados en usos y habilidades compartidas por un colectivo limitado y definido de agentes (arqueólogos/as), entre los que, en general, los márgenes de subjetividad suelen estar más bien acotados, resulta necesario documentar de forma explícita esta condición.

Cuando consideramos el registro arqueológico como una parte del patrimonio añadimos un nuevo nivel de subjetividad que, en el contexto que estamos abordando aqui, resulta especialmente importante. Si inicialmente la idea de patrimonio se consideraba una parte consustancial, intrínseca a una serie de objetos en función de su propia naturaleza (antigüedad, historicidad, autenticidad...), el peso en la definición del concepto de "patrimonio" ha pasado a estar explícita e indudablemente en la existencia de procesos valorativos contemporáneos. Este cambio es nitidamente expresado recientemente de la siguiente forma: "This process [la evolución del concepto de patrimonio] is based on the substitution of an objective logic characterizing the historic monument with a subjective logic of heritage" (VECCO, 2010: 322).

Esto significa que, conceptualmente, lo que llamamos registro arqueológico y patrimonio arqueológico son dos cosas diferentes. Íntimamente relacionadas, sin duda, pero diferentes. El patrimonio no viene dado por la naturaleza de las cosas perceptibles, materiales, sino de las valoraciones realizadas sobre esas cosas. La condición de un objeto como patrimonio no es algo intrínseco de él, sino algo otorgado a través de un proceso de valoración. Y cualquier valoración involucra, por definición, una subjetividad. Más o menos compartida, pero subjetividad al fin. Un ejemplo de los efectos de esto es el hecho de que dos elementos materiales cualesquiera que sean objetivamente iguales (por ejemplo, dos ermitas románicas de similares dimensiones, forma, estructura, elementos decorativos, etc.) pueden ser considerados como bienes patrimoniales de diferente tipo, categoría o grado de protección.

Si hablamos en términos de información geográfica, la forma más habitual en la que se concreta el componente patrimonial del registro arqueológico es la de contornos de delimitación y protección de los bienes. Pero esta "capa" de datos geográficos es diferente a la que representarian los objetos sobre los que se construyen esos bienes. Esto se entiende perfectamente considerando, de nuevo, un ejemplo que puede ser perfectamente típico: la modificación de un elemento material (por ejemplo, la destrucción de una parte de un yacimiento arqueológico) no tiene por qué suponer necesariamente su reconsideración como bien patrimonial, al punto de ni siquiera implicar necesariamente el cambio en la geometría de su contorno de protección como bien. A la inversa, la modificación de la geometría de la protección del bien puede ocurrir por efecto de un cambio en la valoración del yacimiento y no sólo porque la geometría de éste haya cambiado.
Sobre estos dos niveles de subjetividad, todavía podriamos añadir un tercero: el correspondiente a aquellas valoraciones realizadas sobre aquellas cosas que, desde una perspectiva multivocal, cobran significado para otros colectivos diferentes de los expertos en Arqueología o en gestión patrimonial (LABADI, 2007).

Considerar de forma integral la dimensión geográfica del patrimonio arqueológico requiere entender que éste no es sólo un conjunto de elementos materiales concretos, que es sin duda su parte esencial, sino también un conjunto de significaciones y valores que asignamos y construimos sobre esos elementos materiales. Incorporar su temporalidad, incertidumbre y subjetividad son desafios que deben ser abordados'.

\section{Notas}

1 En esta línea, como en la mayor parte de los temas apuntados en este texto, estamos trabajando desde el Laboratorio de Patrimonio, en el marco de los proyectos SPATRIAL ("Definición de un modelo para la representación de aspectos espaciales del Patrimonio Cultural", Plan Nacional de I+D 2010), liderado por César Parcero-Oubiña y MIRFOL ("Metodoloxia Integral para a Representación Formal do Patrimonio Cultural", Plan Galego de I+D 2010), liderado por César González-Pérez.

\section{Bibliografía}

BURROUGH, P. A.; FRANK, A. U. (ed.) (1996) Geographic Objects with Indeterminate Boundaries. Londres: Taylor \& Francis, 1996 DOERR, M. (2003) The CIDOC Conceptual Reference Module. An Ontological Approach to Semantic Interoperability of Metadata. Al Magazine, n. ${ }^{\circ} 24,2003$ pp. 75-92

FISHER, C. T.; FEINMAN, G. M. (2005) Introduction to Landscapes over time. American Anthropologist, v. 107, n. ${ }^{\circ}$ 1, 2005, pp. 62-69

FLORIDI, L. (2005) Is Semantic Information Meaningful Data? Philosophy and Phenomenology Research, v. LXX, n. ${ }^{\circ} 2,2005$, pp. 351-370

JESSOP, M. (2004) The Visualization of Spatial Data in the Humanities. Literary and Linguistic Computing, v. 19, n. ${ }^{3}$ 3, 2004, pp. 335-350

LABADI, S. (2007) Representations of the nation and cultural diversity in discourses on World Heritage. Journal of Social Archaeology, v. 7, n. ${ }^{\circ}$, 2007, pp. 147-170

REDMAN, C. L. (2005) Resilience Theory in Archaeology. American Anthropologist, V. 107, n. ${ }^{\circ}$ 1, 2005, pp. 70-77

VECCO, M. A. (2010) Definition of cultural heritage: From the tangible to the intangible. Journal of Cultural Heritage, v. 11, n. ${ }^{\circ} 3,2010$, pp. 321-324 